\title{
Políticas públicas de fomento de sociedades cooperativas y laborales. Especial referencia a las actuaciones de difusión de la economía social
}

\author{
Luis Diez Ácimas \\ Gerente Territorial de Justicia de Cantabria
}

Sumario: I. Introducción. II. El artículo 129.2 de la Constitución Española. III. La Ley de Economía Social. IV. Política de fomento. 1. Actuaciones que tienen como destinatarias a las empresas de economía social. 2. Actuaciones que tienen como destinatarias a entidades que contribuyen al fomento y difusión de la economía social. 3. Comentarios sobre las actuaciones que tienen como destinatarias a entidades que contribuyen al fomento y difusión de la economía social. 4. Crítica de la evolución de algunas medidas tradicionales de fomento de la economía social. 5. Revisión de las actuaciones realizadas por las administraciones públicas. V. Diferentes actuaciones de divulgación de la economía social. 1. Actos de reconocimiento institucional al cooperativismo y la economía social. 2. Reconocimiento institucional a las empresas de economía social. 3. Actuaciones diversas que contribuyen a acercar la economía social a la sociedad. VI. Conclusiones.

Resumen: Los poderes públicos tienen la obligación de fomentar la economía social. La Administración General del Estado y las administraciones de las Comunidades Autónomas gestionan programas de subvenciones. Estas tienen como objeto principal la creación y consolidación de empresas con forma jurídica de sociedad cooperativa o sociedad laboral. También, se financian actuaciones de entidades asociativas, fundaciones, universidades, ayuntamientos... que tienen como objetivo dar formación en materia de economía social y difundir este sector entre los potenciales emprendedores, los asesores de los mismos y la sociedad, en general. En este campo, creemos que se pueden realizar más actuaciones que mejoren la visibilidad de cooperativas y sociedades laborales. Por último, en este estudio vamos a comentar diversas iniciativas públicas, privadas o mixtas que contribuyen a la divulgación de los principios y valores de las empresas de economía social.

Palabras clave: Economía social. Fomento. Formación. Difusión. Divulgación.

Abstract: The public authorities have an obligation to promote the social economy. The General State Administration and the administrations of the Autonomous Communities manage programs of subventions. These subventions 
have as main object the creation and consolidation of companies with legal form of cooperative society or labor society. They also financed actions of associative entities foundations, universities, municipalities that aim to provide training in the field of social economy management of associations, foundations, universities, town halls, etc. and also spread this sector among the potential entrepreneurs, the consultants of them and society, in general. We believe that in this field more actions that improve the visibility of cooperatives and labour societies can be done. Finally, in this study we will discuss various private, public or mixed initiatives that contribute to the dissemination of the principles and values of the social economy enterprises.

Keywords: Social Economy. Promotion. Training. Diffusion. Divulgation. 


\section{Introducción}

La trascendencia de la economía social va más allá de su importancia en un sentido estricto económico-empresarial, ya que tiene una dimensión social muy relevante derivada, básicamente, de los principios y valores que le son propios; y generalmente, reconocidos. Sólo, teniendo en cuenta esto, se puede explicar el interés constitucional que viene consagrado en el artículo 129.2 de la Constitución Española (C.E.), manifestado explícitamente, en el caso de las sociedades cooperativas y sin nombrarlas expresamente a otras figuras empresariales que tendrían cabida en el sector de la economía social, como son las sociedades laborales.

El interés del legislador por este tipo de sociedades y su fomento se reitera en la legislación estatal, como demuestra la Ley 5/2011, de 29 de marzo, de Economía Social, que supone un fuerte impulso legal a las políticas de fomento. También, se incide en este aspecto en las diferentes leyes de cooperativas, que fijan como objeto de las mismas, no sólo la regulación de este tipo de sociedades; sino, a su vez, determinar las directrices básicas de las medidas de fomento de estas. Lo mismo podemos decir de la Ley 44/2015, de 14 de octubre, de Sociedades Laborales y Participadas, que fija alguna medida fiscal y una disposición general sobre los beneficios en materia de empleo y seguridad social que tengan por objeto impulsar la realización de actuaciones de promoción, difusión y formación de la economía social.

Al amparo de la legislación incentivadora de las fórmulas de economía social, tanto el Estado como las diferentes Comunidades Autónomas convocan ayudas para fomentar la creación y consolidación de estas empresas, así como la generación y mantenimiento de empleo en las mismas. Pero, aquí no queremos reflejar exclusivamente esas medidas de fomento de cooperativas y sociedades laborales, consistentes básicamente en el otorgamiento de diferentes subvenciones a estas empresas, sino que queremos destacar, también, las actuaciones públicas, privadas o mixtas, tendentes a difundir el sector de la economía social entre toda la sociedad. Por lo tanto, no nos centraremos solamente en las políticas de subvenciones, sino que también reflexionaremos sobre las prácticas que contribuyen a dar a conocer la economía social a los emprendedores, los estudiantes, los asesores,... y a difundir las experiencias más positivas; y, así crear un ambiente favorable a su constitución y a participar en las mismas. 


\section{El artículo 129.2 de la Constitución Española}

Las administraciones públicas vienen obligadas a realizar actuaciones de fomento de este sector por imperativo derivado directamente de la Constitución Española de 1978. Esta realiza declaraciones importantes en apoyo del cooperativismo y de la economía social. Su artículo 129.2 dispone que «Los poderes públicos promoverán eficazmente las diversas formas de participación en las empresas y fomentarán mediante una legislación adecuada las sociedades cooperativas. También establecerán los medios que faciliten el acceso de los trabajadores a la propiedad de los medios de producción»»1.

Como podemos observar, se cita expresamente a las cooperativas; pero, no a las sociedades laborales, ya que nacen días después del texto constitucional, mediante una Orden de 12 de enero de 1979.

Este triple mandato constitucional se ha plasmado de diversas maneras en nuestra normativa jurídica. Así podemos ver como se manifiestan en la legislación las previsiones de este precepto:

\section{La promoción de las diversas formas de participación en la empresa}

La obligación constitucional de facilitar la participación de los trabajadores en la empresa tiene diversas manifestaciones en la normativa promulgada con posterioridad a la CE, tales como:

- El Real Decreto Legislativo 2/2015, de 23 de octubre, por el que se aprueba el texto refundido de la Ley del Estatuto de los Trabajadores, configura como un derecho básico de los trabajadores en la relación laboral la información, consulta y participación (artículo $4.1 \mathrm{~g}$ ). Se regulan las figuras de los delegados de personal

1 Calvo Ortega, R., "Las figuras de la Economía Social en la Constitución Española de 1978», CIRIEC-España, n. ${ }^{\circ}$ 47, 2003, pp. 159-174. En este artículo se hace un extenso análisis de este precepto constitucional, en el que se hacen, según el autor, varias afirmaciones de trascendencia; $y$, todas ellas de futuro. El texto indica "promoverán, fomentarán y establecerán». Por tanto, imperatividad y futuro son las notas que se extraen de esta norma. Es un mandato del constituyente a todos los poderes públicos, tanto estatales, como autonómicos; e, incluso, locales. Concluye que resulta difícil, decir si este precepto constitucional ha jugado un papel importante en la creación de empresas de economía social, aunque podamos mostrar cifras positivas del periodo constitucional, siempre queda la duda de saber si el desarrollo que se ha producido es debido al revulsivo de incluir este precepto en la norma constitucional o a otras razones. Entre éstas, destaca el esfuerzo admirable de muchos trabajadores creando y manteniendo empresas asociativas en condiciones siempre difíciles. 
y comités de empresa, consagrando la participación a través de estos órganos, aunque el artículo 61 reconoce otras fórmulas al añadir expresamente «sin perjuicio de otras formas de participación».

- La Ley Orgánica 11/1985, de 8 de agosto de Libertad Sindical, que regula la acción sindical en el seno de la empresa.

- La Ley 31/1995, de 8 de marzo, de Prevención de Riesgos Laborales, que prevé los mecanismos de consulta y participación de los trabajadores en las cuestiones de prevención de riesgos laborales.

- Ley 22/2003, de 9 de julio, Concursal, que otorga a los representantes de los trabajadores competencias para ser oídos, en asuntos tales como el cierre de instalaciones del concursado o en la propuesta de convenio.

\section{El fomento mediante una legislación adecuada de las sociedades cooperativas}

En el cumplimiento de la obligación impuesta a los poderes públicos de fomentar las sociedades cooperativas, mediante una legislación adecuada, podemos constatar la existencia de una amplia normativa sobre la materia. Respecto a la regulación general de este tipo de sociedades, contamos con una Ley de Cooperativas, de ámbito estatal (Ley 27/1999, de 16 de julio), dieciséis leyes autonómicas de carácter general ${ }^{2}$ y diversas leyes sobre aspectos concretos (cooperativas de pequeña dimensión, secciones de crédito,...). Además, contamos con una legislación específica sobre cooperativas de crédito (básicamente la Ley 13/1989, de 26 de mayo) o una regulación del régimen fiscal propio de estas sociedades (Ley 20/1990, de 19 de diciembre, de Régimen Fiscal de las Cooperativas). El análisis de estas regulaciones, nos podría llevar al debate de si esa legislación es "adecuada», como exige la C.E. Evidentemente, este no es el lugar para plantear esa discusión; pero, una proliferación de normas como la descrita no parece el marco legal más propicio para el desarrollo del sector, lo que ha originado, en ocasiones, fuertes críticas 3 .

2 Únicamente, la Comunidad Autónoma de Canarias no dispone de ley propia en materia de sociedades cooperativas.

3 CANO LÓPEZ, A.: «El derecho de la Economía Social: entre la Constitución y el mercado, la equidad y la eficiencia», CIRIEC, n. ${ }^{\circ} 18,2007$, pp. 1-20. 
3. El establecimiento de las medidas que faciliten el acceso de los trabajadores a la propiedad de los medios de producción

En el último inciso de este artículo, se identifica la participación con la propiedad de la empresa. Este precepto ofrece extraordinarias posibilidades para la actuación política, tanto en la selección de los mecanismos de participación como en la determinación cualitativa de los mismos.

Esto se plasma en la promoción de fórmulas fundamentalmente de carácter económico-financiero que contribuyan a la superación de los condicionantes que limitan el acceso a la propiedad de esos bienes y faciliten el acceso al accionariado por parte de los trabajadores. Manifestaciones características de este proceso son las diferentes legislaciones que se han promulgado para regular las sociedades laborales $y$, más recientemente, las sociedades participadas, cuya finalidad es conseguir nuevos modelos de creación de empleo y fomentar la participación de los trabajadores en la empresa, dando cumplimiento, así, a este mandato constitucional.

\section{La Ley de Economía Social (LES)}

La Ley 5/2011, de 29 de marzo, de Economía Social ha contribuido decisivamente a acotar y visualizar, según Montesinos Oltra ${ }^{4}$, un sector de la realidad social de cuya importancia difícilmente puede dudarse, tanto en términos cuantitativos como, sobre todo, cualitativos, que son los que permiten considerarlo un «polo de utilidad social» como se señala en el Informe de la Subcomisión para el Fomento de la Economía Social creada en el seno de la Comisión de Economía y Hacienda del Congreso de los Diputados y justifican el reconocimiento de tratamientos favorecedores o promocionales desde la perspectiva de la actividad financiera de las administraciones públicas.

La promulgación de la LES, pone fin, al menos, de forma momentánea, al intenso debate vivido desde el ámbito doctrinal, el sector empresarial en su conjunto y de las entidades asociativas de las diferentes realidades que se consideraban merecedoras de llevar esta etiqueta. Este debate, incluso, tenía su reflejo en las diferentes administraciones públicas que incluían más o menos tipos de empresas de su ámbito de actuación, dentro de las estructuras administrativas dedicadas a la atención de la economía social.

4 Montesinos Oltra, S., "La Ley de Economía Social, interés general y regímenes tributarios especiales», CIRIEC- España, Revista Jurídica, n. ${ }^{\circ}$ 23, 2012, pp. 1-27. 
La ley fija, por primera vez, en una norma jurídica, cuáles son las empresas que deben ser incluidas en este sector. Al citar las entidades que forman parte de la economía social, que se recogen en el artículo $5^{5}$, sitúa en primer lugar las cooperativas. Su tradición histórica, su presencia en los cinco continentes y en todas las actividades económicas, además de su reconocimiento social y su arraigo en todo el Estado, son las razones que justifican su colocación a la cabeza del listado. También, se cita a las sociedades laborales. Ambas son las figuras principales, por su volumen, del sector de mercado de la economía social y el objeto básico de este estudio.

Para las políticas de fomento de la economía social en España, esta ley es un punto de inflexión; realmente, abre, al menos teóricamente, una nueva etapa en esta materia. Y, decimos teóricamente, porque está pendiente una necesaria y apasionante labor de desarrollo de esta ley. Como indica Pérez de Uralde ${ }^{6}$, «ningún desarrollo reglamentario se ha llevado a cabo a pesar de los mandatos de la LES en tal sentido. Estamos ante una ley de mínimos que precisaría de algún soporte reglamentario para conseguir una cierta eficacia. Pero ni tan siquiera lo más necesario ha sido abordado».

Destacan dos aspectos en los que se aprecia el nuevo marco en el que se mueve este sector:

a) Reconocimiento del sector de la economía social como interlocutor en los procesos de elaboración de las políticas públicas (artículo 7). Lo que constituía una reivindicación histórica del sector, como se exigía ya en 2003 por quien en ese momento ostentaba la presidencia de CEPES 7 .

1. En el ámbito estatal. Se otorga representación en los órganos de participación institucional de la Administración General del Estado que se ocupen de las materias que afectan a sus intereses económicos y sociales a las confederaciones intersectoriales de ámbito estatal representativas. También,

5 El artículo 5.1 de la LES establece que forman parte de la economía social las cooperativas, las mutualidades, las fundaciones y las asociaciones que lleven a cabo actividad económica, las sociedades laborales, las empresas de inserción, los centros especiales de empleo, las cofradías de pescadores, las sociedades agrarias de transformación y las entidades singulares creadas por normas específicas que se rijan por los principios establecidos en el artículo anterior.

6 Pérez de URALDE, J. M.: «Aplicación, desarrollo y reforma de la Ley 5/2011, de Economía Social, ¿un derecho debilitado?», REVESCO Revista de Estudios Cooperativos, Vol. 125, 2017, pp. 134-158.

7 De Castro Sanz, M.: «La economía social como agente económico: necesidad de su participación como interlocutor social», CIRIEC - España, Revista de Economía Pública, Social y Cooperativa, n. ${ }^{\circ}$ 47, extraordinario, noviembre de 2003, pp. 41-57. 
tendrán representación en los órganos de la Administración General del Estado, las organizaciones de ámbito estatal que agrupen mayoritariamente a las entidades de la economía social, en todas aquellas actividades de representación que les sean propias por su naturaleza jurídica y actividad (art. 7.3).

2. En el ámbito autonómico. Declara que las organizaciones, federaciones o confederaciones representativas de cada Comunidad Autónoma tendrán representación en los órganos de participación institucional de las Administraciones de las Comunidades Autónomas que se ocupen de las materias que afectan a sus intereses económicos y sociales. Esta participación se concretará en la forma en que se prevea por las diferentes Comunidades Autónomas.

b) Concepción de una amplia gama de políticas de fomento de la economía social (artículo 8). Se reconoce como tarea de interés general, la promoción, estímulo y desarrollo de las entidades de la economía social y de sus organizaciones representativas. Además, impone a los poderes públicos determinados objetivos en sus políticas de promoción de la economía social, tales como:

1) Remover los obstáculos que impidan el inicio y desarrollo de una actividad económica de las entidades de la economía social. Para ello se prestará especial atención a la simplificación de trámites administrativos para la creación de entidades de la economía social.

2) Facilitar las diversas iniciativas de economía social.

3) Promover los principios y valores de la economía social.

4) Promocionar la formación y readaptación profesional en el ámbito de las entidades de la economía social.

5) Facilitar el acceso a los procesos de innovación tecnológica y organizativa a los emprendedores de las entidades de economía social.

6) Crear un entorno que fomente el desarrollo de las iniciativas económicas y sociales en el marco de la economía social.

7) Involucrar a las entidades de la economía social en las políticas activas de empleo, especialmente en favor de los sectores más afectados por el desempleo, mujeres, jóvenes y parados de larga duración.

8) Introducir referencias a la economía social en los planes de estudio de las diferentes etapas educativas.

9) Fomentar el desarrollo de la economía social en áreas como el desarrollo rural, la dependencia y la integración social. 
Como puede verse se incluyen medidas muy diversas, unas tendentes a eliminar obstáculos jurídicos para la creación de estas empresas, otras dirigidas a difundir, formar, investigar e innovar en este campo, otras a fomentar el sector entre colectivos específicos, especialmente vulnerables y otras destinadas a facilitar la inclusión de la economía social en diversas políticas sectoriales.

\section{Política de fomento}

En este apartado sobre las políticas públicas de fomento, distinguiremos básicamente entre las actuaciones que tienen como destinatarias a las propias empresas y las que van dirigidas a diferentes tipos de entidades para la realización de acciones de difusión de la economía social en diferentes ámbitos.

\section{Actuaciones que tienen como destinatarias a las empresas de economía social}

Como hemos repetido con insistencia, el artículo 129.2 de la CE exige una legislación adecuada como mecanismo para el fomento, en concreto, de las sociedades cooperativas, lo que nos puede llevar a pensar que el legislador constituyente consideró que la normativa preconstitucional al respecto no era la correcta para lograr los objetivos propuestos. Pese a ello, podemos observar un alto grado de continuidad de las políticas de fomento. Con anterioridad a la aprobación de la CE existían medidas fiscales, recogidas en el Estatuto Fiscal de las Cooperativas de 1969 y ayudas provenientes del Fondo Nacional de Protección al Trabajo con destino a financiar inversiones y a la creación de empleo. Las medidas fundamentales de fomento ejecutadas después de la entrada en vigor de la CE son básicamente fiscales, subvenciones con las mismas finalidades y capitalización de la prestación por desempleo; con lo que podemos apreciar esa continuidad básica que anunciábamos anteriormente 8 .

El contenido de las ayudas estatales y autonómicas en esta materia son objeto de análisis pormenorizado en diferentes trabajos, bien referidos a la

8 Calvo Ortega, R.: Sociedades Laborales, Cuadernos Civitas, Editorial Aranzadi, Cizur Menor, 2013, p. 13. 
economía social, en general ${ }^{9} \mathrm{o}$ a alguna figura empresarial en concreto $^{10}$. Así, podemos indicar que se otorgan ayudas destinadas a fomentar la creación y consolidación de empresas y del empleo y aumentar su competitividad; así, de forma meramente enunciativa, tenemos subvenciones a:

- La creación de nuevas empresas con forma jurídica de sociedad cooperativa o sociedad laboral.

- La incorporación de socios a estos tipos de empresas.

- Proporcionar asistencias técnicas con diversas finalidades.

- La realización de inversiones. Tanto subvenciones directas sobre las mismas como bonificaciones del tipo de interés.

- La promoción del desarrollo tecnológico.

- Favorecer la internacionalización de las empresas.

- Incentivar la conciliación de la vida laboral y familiar.

No podemos ocultar, al hablar de estas ayudas, que existen voces discrepantes con la existencia de medidas específicas favorecedoras de las empresas de economía social; pero, los motivos para que éstas existan son claros. Estas sociedades participan de principios y valores (gestión democrática, prioridad de la persona sobre el capital, ...), y gozan de ventajas y potencialidades (creación de empleo estable y de calidad, fijación de población al territorio, generación de cohesión social, modernización y profesionalización del sector agrario, contribución al desarrollo rural, ...) que las hacen merecedoras de un tratamiento específico. Pero, si esto no fuera suficiente para acreditar las medidas de discriminación positiva que puedan otorgarse a las cooperativas, hay que recordar que existe un motivo de excepcional relevancia que justifica ese trato y es el hecho de que éstas dotan fondos, con finalidades específicas, que son irrepartibles cuando los socios abandonan la cooperativa o ésta se transforma en otro tipo de sociedad e, incluso, cuando la misma desaparece ${ }^{11}$. Los va-

9 FajARDo García, G.: «El fomento de la economía social en la legislación española», REVESCO, Revista de Estudios Cooperativos, n¹07, 2012, pp. 58-97. Como ejemplo de medidas de fomento a la generalidad del sector.

10 Chaves Ávila, R., Abad, F., Lowitzsch, J.: «La política económica dirigida hacia las sociedades laborales». En https://even3storage.blob.core.windows.net/anais/77130.pdf. Como ejemplo de fomento de una forma empresarial determinada, en este caso, las sociedades laborales.

11 Rodrigo Ruiz, M. A.: "Mandato constitucional de fomento y fiscalidad de las cooperativas», CIRIEC-España, Revista de Economía Pública, Social y Cooperativa, n. ${ }^{\circ} 47$, extraordinario, noviembre 2003, pp. 199-219. Esta importantísima limitación patrimonial distingue de modo esencial a las cooperativas de las sociedades capitalistas, desde el punto de vista económico, y supone para las primeras un mecanismo peculiar de contribución a la comunidad que demanda, en buena técnica fiscal, medidas correctoras, pues afecta y reduce la capacidad contributiva que en éstas puede ser gravada. Di- 
lores referidos son reconocidos por el preámbulo de la Ley 31/2015, de 9 de septiembre, por la que se modifica y actualiza la normativa en materia de autoempleo y se adoptan medidas de fomento y promoción del trabajo autónomo y de la economía social12, al reconocer que la economía social es fuente de creación de empleo estable, de calidad y no deslocalizable y es una importante plataforma de acceso al empleo para aquellos que, por sus especiales circunstancias, encuentran mayores dificultades de inserción laboral y/o que se encuentran en riesgo de exclusión social. Constituyen, añade, un elemento clave de cohesión social muy necesario tras la larga crisis que ha atravesado nuestro país.

\section{Actuaciones que tienen como destinatarias a entidades que contribuyen al fomento y difusión de la economía social}

Nos referimos, ahora, a las ayudas que tienen como destinatarias a las entidades asociativas de empresas de economía social u otro tipo de asociaciones o fundaciones que tengan entre sus objetivos el fomento de la economía social, las universidades, los ayuntamientos, los colegios profesionales... con la finalidad de fomentar y difundir este sector.

Estas actuaciones no tienen como objetivo inmediato facilitar la creación o consolidación de empresas, sino que pretenden dar a conocer el sector a los potenciales emprendedores, a los profesionales que asesoran a estos, a los profesores y a la sociedad en general, favoreciendo, a medio y largo plazo, el conocimiento sobre el sector, y un posible crecimiento futuro del mismo. Se otorgan ayudas para:

- Ofrecer formación en materia de economía social.

- Elaboración de estudios, trabajos de documentación, análisis e investigación

- Organización de congresos, seminarios, jornadas,...

- Edición de publicaciones, tanto científicas como con destino a los potenciales emprendedores o a los socios y trabajadores de estas empresas.

- Campañas publicitarias para la promoción del sector.

cho de otro modo, ya que buena parte del patrimonio social obtenido con el esfuerzo particular de sus miembros termina revertiendo a la comunidad, parece lógico que las cooperativas contribuyan al sostenimiento de las cargas públicas destinando un menor porcentaje de sus beneficios regulares o periódicos al pago de impuestos.

12 Esta ley modifica el artículo 9 de la Ley 5/2011, de 29 de marzo, de Economía Social, estableciendo incentivos a la incorporación de trabajadores a entidades de economía social. 
- Fortalecer las estructuras asociativas de empresas de economía social.

- Actividades de investigación, docencia y difusión sobre temas relacionados con la economía social realizados por universidades ${ }^{13}$.

3. Comentarios sobre las actuaciones que tienen como destinatarias a entidades que contribuyen al fomento y difusión de la economía social

Entendemos que el panorama actual a este respecto, no es el marco más propicio para conseguir la finalidad propuesta. Pondremos algunos ejemplos de lo que decimos.

3.1. En los programas de formación y difusión vemos constantemente la celebración de congresos, seminarios, encuentros, cursos,... en los que los participantes son de forma reiterada los estudiosos del tema, los dirigentes del movimiento asociativo o de las empresas más importantes del sector, los responsables de la materia en las administraciones públicas; pero, no acceden a ellos habitualmente los promotores de empresas asociativas, los prescriptores de formas jurídicas empresariales (asesores, agentes de desarrollo local, orientadores de empleo, personal de las Cámaras de Comercio,...) que son los que tienen la llave para la creación efectiva de sociedades cooperativas y laborales; pero que, de momento, no son las fórmulas más recomendadas por estos.

3.2. Se otorgan ayudas para el mantenimiento de las estructuras de las organizaciones representativas del sector, financiando sus gastos ordinarios sin exigir ninguna contrapartida. Debe de financiarse a estas entidades, pero como compensación por su labor en la creación de cooperativas y sociedades laborales, de puestos de trabajo, de servicios efectivos prestados a sus asociados, a los emprendedores demandantes de orientación... De esta manera, se conseguiría una mayor eficacia y aprovechamiento de los recursos públicos y una vinculación directa de

13 Juliá, J.F, Melí, E., Lajara, N.: «Universidad, ciencia y economía social», REVESCO, n. ${ }^{\circ} 119$, tercer cuatrimestre, 2015. Destacan la importancia de la universidad en este ámbito y concluyen manifestando, «En relación a la economía social, no hay más camino que potenciar su visibilidad a través de foros, jornadas, etc, pero también trabajando en el reconocimiento de las revistas especializadas en esta temática, de forma que la investigación en este campo sea visible al resto de la comunidad científica y de la sociedad». 
las ayudas a la actividad que realizan las organizaciones en favor de la creación y consolidación de empresas.

3.3. La LES y las diferentes leyes autonómicas de cooperativas reclaman la enseñanza del cooperativismo y de la economía social en los diferentes niveles educativos. Esto es algo que está pendiente y parece que muy lejos de conseguir. Se llega a un puñado de centros de enseñanza secundaria a los que se acercan las entidades asociativas del sector a presentar estos modelos empresariales y a un reducido número de centros universitarios que realizan acciones de difusión, normalmente financiadas con cargo a programas públicos de fomento; pero, no se introduce el estudio de la cooperación y de la economía social, salvo muy loables excepciones, en los programas educativos. En el ámbito universitario, el grado de penetración de la economía social es aún muy bajo ${ }^{14}$.

4. Críticas a la evolución de algunas medidas tradicionales de fomento de la economía social

Podemos afirmar que algunas medidas provenientes de épocas anteriores han visto reducidas claramente las ventajas para las sociedades cooperativas y laborales. Pongamos unos ejemplos:

- Los tipos de gravamen ordinarios del Impuesto de Sociedades en 1990, cuando se aprueba la Ley sobre Régimen Fiscal de las Cooperativas, eran muy superiores a los actuales, y los de las sociedades cooperativas no se han modificado, con lo que la diferencia de tributación entre las cooperativas y otras sociedades se ha reducido considerablemente..

- Las bonificaciones en el Impuesto sobre Actividades Económicas previstas en dicha ley, se han convertido desde 1 de enero de 2003, con carácter general, en exenciones a las empresas de pequeña dimensión.

- La capitalización de la prestación por desempleo prevista en el Real Decreto 1044/1985, de 19 de junio, por el que se regula el

14 Flores Ruiz, D., Guzmán Alfonso, C., Barroso González, M.: «La formación en economía social, análisis de la oferta universitaria de posgrado en España», REVESCO, n. ${ }^{\circ}$ 121, segundo cuatrimestre 2016. Destaca el dato de que «la formación específica de posgrado específica en economía social sólo representa alrededor del $4 \%$ de la oferta total de titulaciones del sistema universitario español en la rama de Económicas y Empresariales. 
abono de la prestación por desempleo en su modalidad de pago único por el valor actual de su importe, como medida de fomento de empleo, que durante mucho tiempo era una medida específica para incentivar su incorporación como socio en una sociedad cooperativa o laboral (o establecimiento como autónomo de trabajadores con discapacidad) se ha generalizado para el inicio de la actividad profesional por parte de los trabajadores autónomos. No cuestionamos que estos puedan acceder a esta medida, solamente lo indicamos para reflejar que las ventajas anteriores se han ido diluyendo.

- La medida fiscal más importante a la que pueden acogerse las sociedades laborales es la libertad de amortización de los elementos del inmovilizado material, intangible e inversiones inmobiliarias, adquiridos durante los primeros cinco años desde la calificación como tal, que se regula en la Ley del Impuesto de Sociedades; pero, esta medida ha perdido su carácter de promoción específica de estas sociedades al extenderse esta medida, con matizaciones, a las empresas de pequeña dimensión en general.

Con estos datos, se acredita que se ha producido una pérdida de las ventajas competitivas que podían tener en otra época las cooperativas $\mathrm{y}$; en menor medida, las sociedades laborales y que aconsejan una revisión de las medidas de fomento de estas, si de verdad se desea dar cumplimiento a los mandatos constitucionales, anteriormente referidos de forma reiterada.

\section{Revisión de las actuaciones realizadas por las administraciones públicas}

De las valoraciones realizadas anteriormente, podemos concluir que la Administración General del Estado, así como las Administraciones de las Comunidades Autónomas con competencias en materia de economía social deben elaborar programas estructurados de fomento de la economía social, no adoptar medidas dispersas, inconexas y reiterativas, como ocurre habitualmente, aunque no hayan demostrado su utilidad. Se debe partir del análisis de los resultados de las medidas implementadas con anterioridad y de la fijación de los objetivos que se pretenden conseguir para determinar las medidas que se deben ejecutar en el futuro.

Estas medidas, una vez constatada su eficacia, tienen que ser estables en el tiempo y no estar sujetas a eventualidades económi- 
cas o cambios políticos, para ofrecer la seguridad a los potenciales promotores de este tipo de empresas de cuál va a ser la respuesta de las administraciones públicas respecto a sus proyectos empresariales.

Para conseguir que las figuras empresariales de economía social calen en el mundo del emprendimiento hay que lograr un mayor conocimiento de las mismas, tanto por parte de los trabajadores y sus representantes, como por los potenciales emprendedores futuros, es decir, los estudiantes universitarios y de enseñanzas medias. Es necesario dar a conocer estas formas empresariales de economía social a los profesionales que asesoran a los emprendedores en los inicios de la actividad, ya que los prescriptores de formas jurídicas empresariales no ofrecen estas fórmulas, habitualmente, a las personas que se acercan a ellos con un proyecto empresarial.

También, sería necesaria la formación específica de los socios; y, en su caso, de los socios trabajadores, ya que ellos son los responsables de fijar los criterios de gestión y los objetivos de su empresa, además de conocer en profundidad el modelo empresarial por el que han optado. En este campo, nos encontramos con la dificultad añadida de que, normalmente, tienen difícil encaje en los programas de ayudas para conseguir financiación pública, porque estos socios y trabajadores no forman parte de los colectivos prioritarios de destino de las acciones subvencionables, al no tener la condición de desempleados.

A la vista de los comentarios vertidos anteriormente, resulta necesario que en la política de fomento y difusión se trabaje de forma conjunta con los colegios profesionales, con las autoridades educativas, con las universidades, con las administraciones locales... para conseguir una mejor penetración de la economía social en estos ámbitos; y, en consecuencia, en el entramado económico-empresarial de nuestro país.

\section{Diferentes actuaciones de divulgación de la economía social}

Exponemos a continuación algunos ejemplos de diferentes actuaciones que contribuyen a la divulgación de la economía social en distintos ámbitos de la sociedad o en esta en su conjunto. Son medidas muy dispares entre sí y a las que nos referimos a modo de ilustración, sin que eso suponga una elección por considerarlas mejores que otras que no indicamos. 
1. Actos de reconocimiento institucional al cooperativismo y la economía social

- Año Internacional de las Cooperativas. La Asamblea General de las Naciones Unidas proclamó 2012 como el Año Internacional de las Cooperativas y resaltó la contribución de estas al desarrollo económico y social, especialmente, su impacto en la reducción de la pobreza, la creación de empleos y la integración social.

Bajo el lema «Las empresas cooperativas ayudan a construir un mundo mejor», el Año Internacional de las Cooperativas se marcó tres objetivos principales:

a) Crear mayor conciencia del público sobre la contribución de las cooperativas al desarrollo económico y social, y al logro de los Objetivos de Desarrollo del Milenio.

b) Fomentar la constitución y el crecimiento de cooperativas, compuestas de personas e instituciones, para abordar sus necesidades económicas mutuas además de lograr una plena participación económica y social.

c) Alentar a los gobiernos y organismos reguladores a implementar políticas, leyes y normativas que propicien la constitución y el crecimiento de las cooperativas.

Con motivo de esta celebración, fueron numerosos los organismos y administraciones públicas que realizaron actos de reconocimiento del cooperativismo y se formularon numerosas declaraciones institucionales en apoyo del sector. Así se hizo por el Congreso de los Diputados, y por numerosos gobiernos y parlamentos autonómicos, diputaciones provinciales y ayuntamientos. Estos actos y declaraciones, que son muy positivos, para visibilizar el mundo cooperativo y que este sea objeto de atención de los poderes públicos y de los medios de comunicación, deberían haber tenido continuidad con otras actuaciones de apoyo a la economía social, una vez conseguida la implicación de las instituciones, y no quedarse en una actuación aislada.

- Día Mundial del Cooperativismo. Es habitual que las entidades asociativas de cooperativas celebren anualmente su día. A veces, las administraciones públicas respaldan estos eventos y participan de los mismos. En el caso de la Región de Murcia, la entidad representativa de las cooperativas de trabajo celebra este día, además de con otros actos, entregando el premio Arco Iris para reconocer a las personas, organizaciones e instituciones que más 
han destacado y mejor representan los valores del cooperativismo. Podemos decir lo mismo que antes, están muy bien esas celebraciones, pero hay que conseguir que se hable por los representantes públicos y los medios de comunicación con mayor asiduidad del cooperativismo y la economía social; y, en ese objetivo, es muy importante la actuación de las entidades asociativas de empresas de economía social.

- Día Nacional de las Cooperativas. En el caso de Nicaragua, por ejemplo, para dar solemnidad a esta celebración, se reconoce este día con una norma con rango de ley. Se declara, por la Ley n. ${ }^{\circ}$ 775, el 19 de febrero de cada año «Día Nacional del Cooperativismo en Nicaragua», obligando a la Asamblea Nacional a celebrar una sesión especial en conmemoración de ese día, al que se invitará a los diferentes representantes del sector cooperativo para que participen. También dispone que los centros de enseñanza realizarán actos conmemorativos y se celebrarán jornadas de información y divulgación. Esta medida se justifica en el preámbulo de la ley con la afirmación de que existen (en el momento de promulgación de la ley, 2011) más de tres mil quinientas cooperativas, con más de doscientos mil asociados y que benefician a un millón de nicaragüenses; además, considera al cooperativismo como un baluarte de la economía social, sobre todo, en dos aspectos fundamentales para la paz social, como son la generación de empleos y la producción alimentaria nacional.

\section{Reconocimiento institucional a las empresas de economía social}

Si antes nos referíamos al reconocimiento al movimiento o al sector en su generalidad, ahora nos referimos a las actuaciones de las administraciones para reconocer a las empresas de economía social que destacan por su trayectoria, generación de empleo, contribución a la igualdad de oportunidades, protección del medio ambiente, carácter innovador, ... así nos encontramos con varias Comunidades Autónomas que convocan anualmente premios para reconocer a estas empresas. Nos referiremos a dos:

a) Premios Arco Iris del Consejo Andaluz de Cooperación. Con estos se reconocen a las cooperativas andaluzas, otorgándose premios a la mejor cooperativa, a la más innovadora, a la mejor experiencia juvenil, a la mejor integración cooperativa,... Ade- 
más, se reconoce a la mejor labor de fomento y a la mejor investigación en la materia.

b) Premios de la Comunidad de Castilla y León al cooperativismo y la economía social. Se reconoce anualmente a la mejor empresa cooperativa y a la mejor iniciativa cooperativa, además de a una empresa con otras formas jurídicas de economía social. Se premia, también, a la persona o entidad que se haya distinguido por su contribución al desarrollo del cooperativismo y la economía social.

3. Actuaciones diversas que contribuyen a acercar la economía social a la sociedad

Recogeremos en este apartado, actuaciones muy diversas, con el único nexo de unión entre ellas, que tienen el objetivo de dar a conocer la economía social a diferentes públicos, más allá del mundo empresarial o científico de la economía social.

a) Teatro. La Dirección Xeral de Traballo e Economía Social de la Xunta de Galicia, ha llevado a cabo un programa de divulgación del cooperativismo en la enseñanza secundaria (dirigida a alumnos de $3 .^{\circ}$ y $4 .^{\circ}$ de ESO), a través de una obra teatral titulada "Coopérate». Es una obra de carácter lúdico y cómico, que divulga el modelo cooperativo de una manera amena y positiva. Conecta con los intereses y el sentido del humor del público destinatario y formula mensajes claros en torno a las cooperativas y a sus valores. La obra se complementa con la realización de una actividad final de reflexión y debate que busca reforzar los contenidos didácticos de la obra, la reflexión activa por parte del público y consolidar con más fuerza los conocimientos sobre cooperativismo que dan sentido a esta actividad.

b) Festival musical. El «Festival Río Grande canta al cooperativismo» es una promoción del Servicio Nacional de Aprendizaje del Cooperativismo del Estado de Rio Grande do Sul, de Brasil. El año 2017, se celebró la 10. a edición de este festival, que eligió para esa edición el lema «Cada día es día de cooperar».

Este festival tiene los siguientes objetivos:

1. Promover la integración de los dirigentes de cooperativas, asociados, colaboradores, familiares y comunidad, conforme se establece en los objetivos del programa de educación y cultura cooperativista. 
2. Promover los principios y valores del cooperativismo para niños, jóvenes, mujeres y comunidad, a través de la música.

3. Proporcionar a los artistas cooperativistas del Estado de Rio Grande do Sul una mayor integración e intercambio de experiencias entre los músicos y poetas, además de proporcionar condiciones adecuadas para que puedan expresar su arte.

4. Estimular a los socios, a los empleados de cooperativas y a sus familiares la participación en eventos culturales, promoviendo el bienestar social y la mejor calidad de vida.

5. Editar en CD y DVD la etapa final del festival.

Para que los autores puedan presentar obras al festival, al menos, uno de ellos, debe ser socio o empleado de una cooperativa regular del Estado de Rio Grande do Sul.

Para potenciar la localidad donde se celebra cada año el evento, al menos, una de las veinte obras seleccionadas para la fase final del festival, deberá ser de autor o autores asociados a una cooperativa, o empleados de cooperativa, establecida en la ciudad sede del evento, promoviendo así el estímulo y la participación de aquella comunidad en el programa de educación y cultura cooperativista.

Entre los títulos finalistas de las dos últimas ediciones, se encuentran algunos tan sugerentes para el mundo cooperativo como "Nosotros somos la cooperación», «El poder de la unidad», «En cada verso un principio», «Hermanos de sueños iguales», "De vivir y cooperar», "Las puertas están abiertas»,...

c) Escuela Cooperativa Móvil. Es una campaña centrada en la divulgación de las potencialidades del cooperativismo como salida laboral dirigida a la juventud gallega en la red de centros "Eusumo» ${ }^{15}$. Es un aula itinerante que cuenta con equipos informáticos y proyector y que, además de asistir a actividades de fomento del cooperativismo (encuentros, ferias, jornadas de divulgación,...), recorre los centros educativos de sus inmediaciones (centros de formación profesional, de formación ocupacio-

15 La red «Eusumo» fue creada por la Xunta de Galicia para promover el cooperativismo y la economía social en todo el territorio de Galicia, por medio de acciones de formación, divulgación y asesoramiento para el autoempleo colectivo. Se configura esta red como un instrumento de acción descentralizada, constituida por las entidades promotoras de la economía social, administraciones locales, centros colaboradores y la propia Consellería a través de la Dirección Xeral de Traballo e Economía Social y del Consello Galego de Cooperativas 
nal, de formación secundaria y centros universitarios) con el fin de promover y divulgar la fórmula cooperativa entre los más jóvenes. Cuenta con personal técnico especializado en cooperativismo que muestra a los alumnos las ventajas de las cooperativas mediante sesiones prácticas. Tiene la finalidad de transmitir a los participantes los valores del cooperativismo, las habilidades sociales cooperativas, los pasos necesarios para crear una cooperativa, así como el análisis de casos de cooperativas de éxito.

Asimismo, también presta asistencia y apoyo técnico a la red de centros «Eusumo» y atención a sus usuarios.

Se trata de una campaña de información y sensibilización social centrada en la promoción de las potencialidades del cooperativismo como salida laboral para la juventud. El autoempleo cooperativo le permite a los jóvenes realizar su proyecto profesional en un marco participativo, democrático y autogestionado que promueve el desarrollo de las capacidades individuales y colectivas puestas a disposición de un proyecto empresarial emprendido en común. Para esto los técnicos imparten charlas formativas en grupos de 25 alumnos aproximadamente con explicaciones didácticas y con puesta a disposición de material de divulgación y formación cooperativa. Asimismo llevan a cabo talleres de elaboración de proyectos cooperativos, donde los técnicos asesoran y elaboran junto con los alumnos proyectos empresariales cooperativos. Otras de las actividades llevadas a cabo en la Escuela Cooperativa Móvil son la elaboración de seminarios de generación de ideas.

Además de los alumnos, los técnicos imparten formación al profesorado de cada centro a través de un módulo de conocimientos técnicos en cooperativismo específico, con el objetivo de que la campaña tenga continuidad a través de su labor docente.

\section{Conclusiones}

Entendemos que tanto las administraciones públicas, como las empresas de economía social y sus entidades asociativas representativas deben hacer un gran esfuerzo por fomentar y divulgar las potencialidades de este sector. La colaboración entre administración y empresas es imprescindible para lograr objetivos relevantes en esta materia.

Se debe conseguir una mayor presencia de la economía social en la formación, en todos los niveles educativos; así como tener un contacto 
mayor con los potenciales emprendedores y los profesionales que les orientan y asesoran en las fases iniciales de sus proyectos.

Creemos que todos los agentes implicados en el desarrollo de este sector tienen que conseguir una mayor visibilidad del mismo por parte de la sociedad en general, por lo que es conveniente realizar acciones innovadoras, que despierten el interés de los medios de comunicación y con un amplio potencial de destinatarios.

\section{Bibliografía}

CANo López, A.: «El derecho de la Economía Social: entre la Constitución y el mercado, la equidad y la eficiencia», CIRIEC, n. ${ }^{\circ} 18,2007$, pp. 1-20.

Calvo Ortega, R.: «Las figuras de la Economía Social en la Constitución Española de 1978», CIRIEC-España, n. ${ }^{\circ} 47,2003$, pp. 159-174.

Calvo Ortega, R.: Sociedades Laborales, Cuadernos Civitas, Editorial Aranzadi, Cizur Menor, 2013.

Chaves Ávila, R., AbAD, F., Lowitzsch, J.: «La política económica dirigida hacia las sociedades laborales». En https://even3storage.blob.core.windows.net/ anais/77130.pdf.

De CASTRO SAnZ, M.: «La economía social como agente económico: necesidad de su participación como interlocutor social», CIRIEC - España, Revista de Economía Pública, Social y Cooperativa, n. ${ }^{\circ} 47$, extraordinario, noviembre de 2003, pp. 41-57.

Fajardo García, G.: «El fomento de la economía social en la legislación española», REVESCO, Revista de Estudios Cooperativos, número 107, 2012, pp. 58-97.

Flores Ruiz, D., Guzmán Alfonso, C., Barroso González, M.: «La formación en economía social, análisis de la oferta universitaria de posgrado en España», REVESCO, n. ${ }^{\circ} 121$, segundo cuatrimestre 2016.

JuliÁ, J.F., MeliÁ, E., LAJARA, N.: «Universidad, ciencia y economía social», REVESCO, n. ${ }^{\circ} 119$, tercer cuatrimestre, 2015.

MonTESINOS OLTRA, S.: "La Ley de Economía Social, interés general y regímenes tributarios especiales», CIRIEC- España, Revista Jurídica, n. ${ }^{\circ}$ 23, 2012, pp. 1-27.

Pérez de URALDE, J. M.: «Aplicación, desarrollo y reforma de la Ley 5/2011, de Economía Social, ¿un derecho debilitado?», REVESCO Revista de Estudios Cooperativos, vol. 125, 2017, pp. 134-158.

RodRIGo RuIz, M. A.: "Mandato constitucional de fomento y fiscalidad de las cooperativas», CIRIEC-España, Revista de Economía Pública, Social y Cooperativa, n. ${ }^{\circ} 47$, extraordinario, noviembre 2003, pp. 199-219. 